\title{
Mamae Nui me te Takiwātanga: Surplus suffering and autism spectrum disorder in school social work practice
}

\author{
Liam M. Oades, Counties Manukau District Health Board
}

\begin{abstract}
INTRODUCTION: This research investigates social work interventions available for Social Workers based in primary schools in Aotearoa New Zealand, to address surplus suffering related to autism spectrum disorder (ASD). The aim of this research is to explore possible interventions by reviewing literature, and investigating the practice of professionals, in order to discern the best possible practice. The research questions that will be investigated are: 1) How do social workers in primary schools address the surplus suffering of students?; and 2) What interventions are employed when working with children on the spectrum? There is limited relevant literature; however, the published material suggests that most social workers in schools who work with children on the spectrum employ social-ecological perspectives.
\end{abstract}

METHOD: Qualitative methodologies have been employed, focusing on semi-structured interviews that were designed to answer the pre-set questions while also taking note of other concepts and ideas raised by the interviewees. This study has employed social-ecological theory, as well as social theories of disability.

FINDINGS: This research has found that, while social workers employ social-ecological interventions readily, they are reluctant to engage in potentially beneficial therapeutic techniques.

IMPLICATIONS: The implications suggested by this research are the need for diversification in social work training, and the need for further research to discern the best school social work practice.

KEYWORDS: Autism; SWIS; school; neuro-diversity
Nobody realizes that some people expend tremendous energy merely to be normal.

\section{(Albert Camus)}

Having been diagnosed with Asperger's Syndrome in primary school, the above quote has always resonated with me, as I too, struggled to be normal, and instead found I was isolated, bullied, and misunderstood throughout my education. In my social work studies, I sought to better understand how people like myself could be helped by school social workers.

Philosopher Jean-Paul Sartre famously proclaimed, "Hell is other people."

This mantra may explain surplus suffering in the simplest possible terms. The term surplus suffering was used by Clarke and
AOTEAROA

NEW ZEALAND SOCIAL WORK 33(1), 55-66.

CORRESPONDENCE TO:

Liam M. Oades

Liamoades@gmail.com 
Van Amerom (2007) to describe the result of stigma and superfluous suffering caused by medical treatments. In the context of this research, surplus suffering is used to refer to any and all suffering caused by conditions outside of the purview of their actual impairments or limitations/needs, such as children with autism spectrum disorder (ASD) being isolated, due to how others perceive them and their diagnosis, irrespective of the actual behaviour or characteristics of the children. In this way, surplus suffering can be considered as disenabling created by society and systems around a person, rather than the person themselves (or their disability), and is comparable to the ideas of "disableism" as outlined by Thomas (2012). As an example, while unusual language patterns are a common symptom of ASD (Shearer et al., 2006), the resultant bullying is surplus suffering. This can manifest as peer rejection, isolation within classes, or teachers classing students as being "too hard" due to the diagnosis. There is a relative paucity of literature regarding both surplus suffering and ASD in social work. Furthermore, the majority of the available literature regarding social work practice and autism, relates to surveys of social workers in order to find patterns in practice; see Foster (2015), Eveslage (2012), and Grasu (2015).

There are no official statistics for autism in Aotearoa New Zealand, however Autism New Zealand (2020) suggests that the frequency may be as high as one out of every 54 people. Kids Health (n.d.) suggests that the number of children on the spectrum may be approximately one out of every 100 children in Aotearoa New Zealand. Internationally, the numbers are expected to rise (Elsabbagh et al., 2012; D'Astous et al., 2016; Suresh, 2018).

This article will report on a small study that investigated the nature of social workers' interventions regarding surplus suffering in primary schools. Two questions were investigated: 1) How do social workers in primary schools address the surplus suffering of Autistic students? And 2) What interventions are employed when working with children on the spectrum?

\section{Literature review}

\section{Definition of ASD}

ASD is classified as a neurodevelopmental condition that affects a person's social, cognitive and sensory processing abilities (Autism NZ, 2020). As a spectrum, it encompasses "classical autism", Asperger's syndrome, pervasive developmental disorder not otherwise specified (PDDNOS), childhood disintegrative disorder, and Rett syndrome (Sussman, 2008). It is traditionally characterised by a deficit perspective, with focus on the characteristics of challenges which are usually framed as inabilities or deficits, regarding behavioural management, social cognition, sensory management and joint attention (American Speech Language Hearing Association, 2019). As a result of these characteristics, it is generally considered a developmental disability (Centre for Disease Control, 2018), despite the heterogeneity of autistic characteristics and arguments about the exact nature of autism, (Hens, 2019).

This literature review will focus on material related to addressing surplus suffering, and discuss ways in which social workers can work with people on the autism spectrum to ensure the best results, that minimise both inherent and surplus suffering. As previously stated, although there are no official statistics for autism in New Zealand, it is estimated that approximately one out of every 54 people is on the spectrum (Autism New Zealand, 2020). However, international trends suggest that this can only be expected to rise- it has not been determined if this due to a genuine increase of prevalence or improvements made in screening techniques, as well as greater public awareness around ASD (D'Astous et al., 2016; Elsabbagh et al., 2012; Suresh, 2018). 


\section{Interventions}

Based on reviews of the limited literature, there appear to be two primary types of intervention used by social workers in schools (SWIS) in general when working with students with ASD and their families. These are social-ecological, and therapies rooted in pragmatic language skills.

\section{Social-ecological interventions}

Several authors used the term socialecological to refer to a series of interventions that work with both the child and the ecosystem around them (Foster, 2015). These interventions emphasise the child in the context and acknowledge the strain and stress that the families of autistic children can experience. Regarding social-ecological interventions, Foster (2015) surveyed 65 social workers regarding their practice with students with ASD and found that workers primarily focused on socialecological interventions. Eveslage (2012) supports this by emphasising the need to coordinate external supports for families. Both Foster (2015) and Eveslage (2012) argue that this approach is paramount to addressing familial isolation, as discussed by Grasu (2015), who examined the role of school social workers when working with families and the wider contexts of the child, as well as Kayama and Haight (2013), Minhas et al. (2015) and Terry (2015) in their empirical studies related to autism, disability and family stigma. Foster (2015) outlined the social-ecological approaches for school social workers working with children on the autism spectrum, specifying interventions such as: supporting families, and collaborating with multi-disciplinary teams. Foster (2015) also found that SWIS provided psycho-social education to those in the children's ecosystem, such as peers, teachers and even family. VanBergeijk and Shtayermman (2005, as cited in Foster, 2015) suggested that social workers create support groups for families, to create additional support systems. Furthermore, in considering macro contexts, both Foster
(2015) and Eveslage (2012) argued that school social workers needed to consider working towards policy changes, addressing misconceptions held by staff, and facilitate long-term support and change within school environments. This approach is reinforced by the survey data compiled by Foster (2015).

\section{Pragmatic language interventions}

There is a clear link between ASD and struggles related to pragmatic language (Klusek et al., 2014). Both Klusek et al. (2014), and Abdoola et al., (2017) define pragmatic language as the ability to adapt a person's speech to social contexts. Abdoola et al. (2017) and Scattone (2007) outline the use of group interventions that assist children gaining proficiency in pragmatic language. While both Foster (2015) and Eveslage (2012) discuss the possibility of social workers engaging in interventions related to pragmatic language, Foster (2015) found that few workers did so. This may be due to debate about the effectiveness of pragmatic language interventions. Whilst Parsons et al. (2017) found overall positive results for pragmatic interventions, Plavnick et al. (2015), and Adams et al. (2012) question the validity of the interventions by suggesting that the therapies were impractical and yielded negligible results. Grasu (2015) disagrees with this and suggests it to be viable in a school social work context. As a result, Sheridan (2012) argues that further research is needed to test the practicalities and effectiveness of such interventions.

In response to these corrective interventions, some writers have raised ethical questions. Shavrina (2014) compared the medicalisation of ASD to the medicalisation of homosexuality. Both Shavrina (2014) and Clarke and Van Amerom (2007) highlighted that the medical perspective of ASD is contradictory to how many people with ASD see themselves. Hens (2019) stated that that this debate had to be considered when working with ASD, as many on the spectrum saw it as their identity, while people on the spectrum perceived professionals seeing 
it as a condition to either cure, ameliorate or in some way change the person. This perspective is exemplified by Oberman (2008) who argued that the functional issues associated were severe enough to warrant a "disability" classification. Oberman (2008) does not, however, answer the question raised in Ripamonti (2016), as to when difference becomes disability, and why disability is treated as inherently negative. Nor did it address the concerns raised by Dinishak (2016) about the concept of disability creating a standardised human mould, that workers may endeavour to force people into. Despite this, neither Ripamonti (2016), nor Shavrina (2014) address how to approach the practical issues associated with ASD, such as difficulties in socialising, communication or obsessive behaviours (Sussman, 2008).

The paucity of literature regarding ASD and school social workers reflects the need for greater research into interventions to address the surplus suffering of school children with ASD. Social-ecological interventions can address a degree of suffering, but are stifled by a lack of resources, often forcing workers to advocate for policy changes to allow them to operate effectively. Pragmatic language interventions are lacking enough evidence to be uniformly employed and require more research. This presents more issues regarding the ethics of such research and requires ethical discussions about what constitutes a "standard human." As a result, more research into both social-ecological and pragmatic language interventions is needed.

\section{Methodology}

This study used the case study method of research. Since case studies are in-depth investigations of a single case or unit (Gilgun, 1994), the case study method was beneficial for this research because it is focused on practical applications. Generally, case studies focus on tacit knowledge, what workers actually do in real work environments as opposed to in theory (Greenwood \& Lowenthal, 2005). Case studies in this context allowed this research to explore what social workers do and gain a practical understanding of their actions in practice. At the same time, case studies are also cohesive with interpretive paradigms (Thanh \& Thanh, 2015). This is because, according to Thanh and Thanh (2015), the case study method is designed to provide qualitative data that allow for researchers to gain better understanding of situations in a wider context, and the interpretive paradigm is designed to analyse qualitative data, without searching for an absolute conclusion.

\section{Research paradigm}

This research is rooted in the interpretive paradigm, as the methods and philosophical background centres on unique lived experiences at the expense of objective, universal realities and is based on a desire to understand socially constructed realities, and hermeneutics (Chilisa, 2012). The interpretive paradigm was chosen because it is useful for discerning, not only the nature of the interventions, but the underpinning understanding of ASD, as the research was able to discern what aspects of ASD and the social environment need to be addressed. A focus on context is also an important aspect of the interpretive paradigm, as it allowed a focus on the understanding of the individual workers, and explore how their understanding and perspectives, as well as other contexts, affect the interventions (Thanh \& Thanh, 2015). When used together with the case study methodology, interpretivism allows for the creation of rich, detailed, and non-numerical data. This style allows researchers to explore situations and questions, as well as the answers, while also acknowledging the unique backgrounds, contexts, and philosophy of the workers themselves (Chilisa, 2012; Ponelis, 2015).

\section{Method}

Interviews were conducted with four professionals in order to better understand both the interventions employed and their limitations. Three of the interviewed 
professionals were school social workers (Mary, Natalie, and Anne) while the fourth worker was a behavioural psychologist (BP) working at a multi-disciplinary private practice specialising in autism (Sophie). Whilst the interviews with Natalie, Anne and Sophie were conducted face to face, Mary offered a written response to the questions as she was unavailable for faceto-face meetings. These interviews allowed the researcher to gain an understanding of the practice of the four workers, as well as an insight into their experiences and understanding of autism, surplus suffering, and other relevant phenomena (Creswell, 2003; Gill et al., 2008). The interviews were semi-structured to facilitate a more fluid conversation that allows the interviewee to discuss broader ideas. This is especially useful when examining new topics, or topics with sparse information (Adams, 2015). Once the interviews were completed, thematic analysis was employed to identify recurring themes within the answers, related to both the topics and the understandings of the interviewees (Vaismoradi et al., 2013).

The interview and research questions were designed to investigate how social workers addressed surplus suffering. This was achieved by investigating what kind of social-ecological and pragmatic language interventions were employed, and how they could address surplus suffering, either directly (such as addressing a school culture of bullying), or indirectly (such as pragmatic language interventions to address social skills to address loneliness from a lack of reciprocal friendships in the long term). In this research, surplus suffering was defined as when superfluous suffering is associated with a person's diagnosis but is not caused by the condition diagnoses; an example of a child being teased by classmates for being bald as a result of chemotherapy is offered.

\section{Ethics}

This research received ethical approval from Manukau Institute of Technology, and as such, the research was guided by the eight principles of the Manukau Institute of Technology's (2017, p. 4) ethical guidelines. These principles are:

1. informed and voluntary consent;

2. respect for rights of privacy and confidentiality;

3. minimisation of risk;

4. limitation of deception;

5. social and cultural sensitivity;

6. research adequacy;

7. avoidance of conflict of interest;

8. respect for property rights.

Of particular significance to this study was principle six, which requires that research both contributes to the education of participating researchers, as well as contributes "to the advancement of knowledge to an extent that warrants the cost to participants." (Manukau Institute of Technology, 2007, p. 17) The research was designed to ensure that the knowledge collected had actual practice value. Information about participants has been stored confidentially. Pseudonyms have been used for this report. The information of each interviewee will be held by the Manukau Institute of Technology for six years before being destroyed. An information letter and consent form were provided to the interviewees prior to the commencement of the interview. When the project is completed, each interviewee will be provided with a hard copy of the research report.

\section{Findings and discussion}

\section{Surplus suffering}

When asked about the term surplus suffering, all four interviewed professionals agreed that the term, with the definition offered, applied to ASD. Both Anne (school social worker) and Sophie (BP) 
identified rejection and isolation as common themes. Anne said, "I see a lot of social and peer rejection, and isolation a lot of misunderstandings with teachers and staff members and other people in the school community. Probably misunderstanding from parents too." While Sophie (BP) identified issues around social skills as relevant, she also argued that stigma arises from the autistic label, stating "also sometimes a label, and that can create the stigma around autism as well as people being uneducated about autism as well. That can cause suffering too, because people do not know how to interact with them."

School social worker Mary further identified an oppressive element to surplus suffering, stating "... once people know they have ASD diagnosis, they treat them differently and work on trying to get them to be like everyone else." This attitude highlights another aspect of surplus suffering: how bias and stigma can lead to oppressive attitudes. Iannuzzi et al. (2015) have argued that ASD has more in common with subcultures characteristically than disabilities. Sub-culture can be understood as a group of people with an identity, based on interests or characteristics, within a larger group (ergo it can be separated from cultures with racial underpinnings, such as Tikanga Māori or the culture of Highland Scots). Iannuzzi et al. (2015) have argued that any worker who does not take a (sub)culturally appropriate perspective is acting oppressively: what Young (2003) calls "cultural imperialism." In this context, cultural imperialism is defined as the oppressive imposition of one set of cultural norms onto another group (McLean, 2011). This can be linked back to Oberman's (2008) arguments. It is worth noting that even here, the questions of Ripamonti (2016) remain unanswered and may be worthy of more consideration and research.

The research of Clarke and Amerom (2007) and Shavrina, (2014) reiterates that ASD has more in common with subcultures than other disabilities, and so an approach that is (sub) culturally appropriate within the domain of "disability culture," may be beneficial for social workers and those they work with. The interviewees did not discuss the possibilities for (sub)culturally appropriate interventions, and it presents an opportunity for future research into disability culture, and how this relates to school social work regarding children on the spectrum.

\section{Isolation and social skills interventions}

Rotheram-Fuller et al. (2010), found children on the autism spectrum were less likely to have reciprocal friendships, and be well less accepted than other peers. Although, according to Masten et al. (2011) there is a scarcity of literature that relates to the perception of isolation for people with ASD. Masten et al. (2011) found isolation and rejection to have the same psychological effect on neuro-typical students. Memoirist John Elder Robison (2008, p.226) wrote of his isolated childhood:

And all those child psychologists who said "John prefers to play by himself" were dead wrong. I played by myself because I was a failure at playing with others. I was alone as a result of my own limitations, and being alone was one of the bitterest disappointments of my young life.

Social isolation was identified by two professionals, Anne, and Sophie, as a common issue related to ASD, and as an aspect of surplus suffering. In both instances, the professionals identified the need to address the issues related to social skills inherent to most definitions of ASD (Dinishak, 2016), as a way to deal with this aspect of suffering. Both professionals discussed therapeutic interventions as possible mechanisms. When shown the work of Abdoola et al. (2017), regarding therapeutic techniques to improve the social skills of children on the autism spectrum, Anne identified the social skills programmes they had been running which served a similar function, such as a drumming group 
that has allowed ASD students "to learn simple skills such as reading the person next to you, oh they're just about to finish ... what does their face look like? Oh, they're prompting me to start." Mary identified the use of games to build social skills as well as the use of social stories designed to improve the quality of social interactions for people with ASD, the validity of which are discussed by Karal and Wolfe (2018) as a means to assist children in learning social skills. Sophie (BP) stated that their therapies can have a similar function as they are trying to help children to interact with others and communicate with others more functionally. This suggests some social workers may need to consider inter-disciplinary practices when practical, as such groups would be traditionally considered the domain of occupational therapists.

As previously stated, Scattone (2007), and Abdoola et al. (2017) have outlined the use of therapeutic interventions that address pragmatic language difficulties common amongst people with ASD. Sophie (BP) identified this as an indirect treatment for what she considered to be a root cause of surplus suffering, the difficulties of communication which lead to isolation and stigma. Both Scattone (2007), and Abdoola et al. (2017) argued that pragmatic therapies could address this issue, and the school social worker believed this to be within the mandate of SWIS.

Such interventions present an interesting possibility for addressing social isolation. Despite a scarcity of written literature to support these interventions, the data suggest that school social workers see these interventions as appropriate methods to alleviate the social isolation that contributes to surplus suffering of people on the autism spectrum.

\section{Changing school climate and policy issues}

Although the term school climate was not used, three of the four professionals interviewed identified issues with the school climate as contributing to surplus suffering. School climate can be defined as the amalgamation of many social factors in a school, such as the relationships between stake holders, the values of the school, and the attitudes fostered by the school and held by students, staff, or parents regarding tolerance, and inclusivity (Iachini et al., 2017; Preble \& Gordon, 2011). As such, this should be distinguished from isolation in schools, as discussed previously. While school climates can include isolation, the concepts are not mutually exclusive, as a school climate can also include patent bullying, harassment, or violence and discrimination (Preble \& Gordon, 2011). Anne identified surplus suffering caused by misunderstandings between teachers, students and staff, and people with ASD. Natalie explained that she sees children carrying biases from home as to what is normal (in doing so, she aligned biases of normal behaviour to biases regarding religion and colour), and that she seeks to create a school that is more tolerable. Mary stated that it was part of the school social worker role to "promote inclusion, helping other children understand the individual differences."

Sophie and Anne identified that teachers often put such students in the "too hard basket" (while stipulating that this was not a universal rule and not all teachers did this). Anne stated that she had seen a lot of "misunderstandings with teachers and staff members." Sophie said:

One thing that I've found is that when teachers do not have enough of an understanding around ASD, they tend to put those children in the too hard basket or they're the naughty ones, or too difficult to deal with.

Natalie made a similar comment: "some teachers will see that diagnosis and label that child as difficult, not realising that there is support and they can still work with themagain like a 'normal' child, and not have it have such a major impact." All workers 
identify that, in some cases, it is necessary to educate teachers about ASD (as well as other learning difficulties) in order to lessen this aspect of surplus suffering, as well as the need to educate the wider community to lessen the prejudice.

Regarding surplus suffering, each of the four interviewed professionals highlighted anecdotal evidence of children on the autism spectrum in schools, suffering due to both bullying from peers and conflicts / tensions with teachers. This suggests that cultural issues, as well as the school climate, can and do contribute to surplus suffering. School social workers will need to address this. Hwang et al. (2018) found children on the autism spectrum were more likely to be victims of bullying and there is also anecdotal evidence of bullying behaviour towards children on the spectrum from parents of other children (Robert-Domolaize, 2019). This suggests cultural issues in schools are causes of surplus suffering for children on the spectrum. Ann addressed the limitations of her role as a SWIS, while also paraphrasing a sentiment raised by Natalie, stating "I think at the end of the day what we can do as SWIS workers is create an environment where that kid feels understood, and feels like a human being while they're with us."

Despite there being little literature directly related to this, Testa (2011) recommends that interventions within a school context would require anti-oppressive and community development models in order to be conducive to school-wide change. Social workers may also wish to consider the ideas of Iannuzzi et al. (2015), who considered that autism should be treated more like a culture than a diagnosis and, as such, principles of cultural competence need to be considered. This idea is supported by Shavrina (2014) and Clarke and Van Amerom (2007), as well as the neurodiversity movement, which characterises ASD as being an acceptable variation between peoples (Robison, 2013). Openshaw (2018) stated that it is the primary purpose of a school social worker to ensure students thrive in the school environment thus making school climates a domain of SWIS. Although, as Higgins (2005) argues, changing the values, practices, pedagogy or even attitudes of a school requires the cohesion of an entire staff. It is important to note that, although each of the domains mentioned in this paragraph have a different interpretation of culture, this does not make the ideas presented by each discipline (about how to work with culture) contradictorythey can be used together in practice.

The three social workers identified issues at a community level that are relevant to the school social worker role in addressing surplus suffering. Social ecological systems theories (Ungar, 2002) suggest frustrations experienced by social workers with the school climate may reflect greater systemic issues and a need for social workers to work within a macro context. Natalie specifically pointed out a lack of consultation between policymakers and social workers regarding educational policy that affects social work.

\section{Working with whānau}

When asked about interventions and supports that affected the entire whānau, Natalie (a school social worker) spoke about the importance of building a relationship with the whānau "It's just having constant open communication. I work alongside families and I like to incorporate what works for them." Regarding direct work with whānau, Anne spoke about "providing psycho-education around what ASD looks like, and what kind of interventions we can have to make sure that the child has a solid routine, and to deal with that rigid thinking and all that kind of stuff." Sophie (BP) spoke of the need to be efficient with time and money "I prefer to do intensive therapy, you know, the more hours the better. But if the parents can't afford that, I would rather work with them and teach them the skills needed."

It is also important to foster external supports for the whānau, in order to address 
long-term needs. Mary, in her written response, wrote about 1: Connecting them to support systems outside the school. 2: Connecting them with the school as they feel alienated when the school environment seems inconsiderate of their needs and what they are going through with their needs.

These familial interventions are aligned with similar research. Foster (2015) surveyed 65 American SWIS and found that working with the families as a whole was contentious among some workers who believed that their sole mandate was to work with the children in educational matters. Despite this, Foster (2015) found that one fifth of workers also performed family counselling, transition planning, and worked with support groups. These workers, according to Foster (2015) also stated that, in some cases, creating new support networks was necessary, and a part of practice and assisted in communication between families and schools. Readers should be aware of the differences between American and Aotearoa New Zealand social work practices when evaluating these readings, as "counselling" is not considered a social worker's role in Aotearoa New Zealand. However, it is worth noting that the interviewees did validate the need to involve outside support systems in familial interventions, as suggested by Foster (2015). A research project on a similar scale to Foster's (2015) survey in Aotearoa New Zealand may be necessary in order to ascertain a more comprehensive overview of how school social workers work with people on the spectrum in general within the unique ethnic and cultural contexts of Aotearoa New Zealand.

Although the professionals interviewed did not discuss parental stress, evidence of family stress impacting children (Payne, 2014) as well as evidence of familial struggles associated with ASD (Shepherd et al., 2017) allow us to infer that addressing the struggles of families associated with ASD is a pre-requisite to addressing the surplus suffering of students. This can be achieved through socio-ecological interventions that seek to build supports outside the preexisting (and often short term) school and family supports. These could include the formation of support groups for families or people on the spectrum, as well the involvement in the creation of educational resources where there is a lack of external supports for the worker to refer whānau to.

\section{Conclusion}

In summary, this research sought to discern how social workers can address the surplus suffering of people with autism spectrum disorder. By using semi-structured interviews, patterns of interventions were identified that aligned with the dominant discourse in the literature. This research identified that the entirety of the small group of workers interviewed agreed that the term and concept of surplus suffering was appropriate to some extent: that children on the spectrum suffer from the actions of others when they react to the diagnosis of autism. Other identified themes include individual and whānau interventions and the need to address issues within school cultures.

A lack of relevant literature and research regarding school social work practice and ASD has been highlighted throughout this research by multiple authors in multiple contexts. Further research is needed to discern the most effective interventions for school social workers to employ when working with people on the autistic spectrum. This research, as well as other research material, further implies that there is a need for diversification of skills, and extra training needed for social workers looking to work with autistic children. This research also suggests there is a need for workers to address issues that have ramifications for the entire school community, as well as issues at a policy level. This may involve writing submissions to Select Committees or advocating for changes in policy changes at different levels of administration and government. As 
such, the use of community development / organisation techniques may be beneficial to address the stigma and ignorance that appears to be at the root of surplus suffering. Future research into school social worker practice may also be helpful in establishing a (sub)cultural approach to ASD, to allow workers to accommodate the fact that ASD is as much a culture as a diagnosis, if not more so.

The workers interviewed demonstrated that, despite a paucity of literature, social workers will find ways to work with ASD and to benefit these students. The majority of the practice highlighted in this report aligned with the literature. The exception to this was the use of pragmatic language interventions. While some research identified pragmatic language therapies as a possible means of intervention, and one worker used them, the majority of interviewed workers did not see it as part of the school social work role. Despite this, school social workers appear to be well equipped and positioned to, not only experiment with therapeutic approaches such as pragmatic language interventions, but also in community development. Such interventions would be useful to address issues within school cultures, and, as such, school social workers may wish to consider training in this area as well.

Accepted 26 January 2021

Published 25 April 2021

\section{References}

Abdoola, F., Flack, P. S., \& Karrim, S. B. (2017). Facilitating pragmatic skills through role-play in learners with language learning disability. The South African Journal of Communication Disorders = Die Suid-Afrikaanse tydskrif vir Kommunikasieafwykings, 64(1), 1-12. doi:10.4102/sajcd.v64i1.187

Adams, C., Lockton, E., Freed, J., Gaile, J., Earl, G., McBean, K., Nash, M., Green, J., Vail, A., \& Law, J. (2012). The Social Communication Intervention Project: A randomized controlled trial of the effectiveness of speech and language therapy for school-age children who have pragmatic and social communication problems with or without autism spectrum disorder. International Journal of Language \& Communication Disorders, 47(3), 233-244. https://doi-org.ezproxy.manukau. ac.nz/10.1111/j.1460-6984.2011.00146.x
Adams, W. C. (2015). Conducting semi-structured interviews. In J. Wholey, H. Hatry, \& K. Newcomer (Eds.), Handbook of practical program evaluation (pp. 492-505). doi:10.1002/9781119171386.ch19

American Speech Language Hearing Association. (2019). Autism. https://www.asha.org/PRPSpecificTopic.aspx?fo Iderid=8589935303\&section=Signs_and_Symptoms

Autism New Zealand. (2020). Definitions. https://www. autismnz.org.nz/definitions/

Centre for Disease Control. (2018). What is autism spectrum disorder? https://www.cdc.gov/ncbddd/autism/facts.html

Chilisa, B. (2012). Indigenous research methodologies. SAGE.

Clarke, J., \& Van Amerom, G., (2007). "Surplus suffering": Differences between organizational understandings of Asperger's syndrome and those people who claim the "disorder." Disability \& Society, 22(7), 761-776. doi:10.1080/09687590701659618

Creswell, J. (2003). Research design (2nd ed.). Sage.

Dash, G., \& Mohan, A. K. (2015). Scope and challenges of social work in schools: Perspectives of teachers and social organizations. International Journal of Applied Research. 1(11), 550-556. http://www. allresearchjournal.com/archives/2015/vol1issue11/ PartH/1-11-23.pdf

D’Astous, V., Manthorpe, J., Lowton, K., \& Glaser, K. (2016). Retracing the historical social care context of autism: A narrative overview. British Journal of Social Work, 46, 789-807. doi:10.1093/bjsw/bcu131

Dinishak, J. (2016). The deficit view and its critics. Disability Studies Quarterly, 36(4). http://dsq-sds.org/index

Elsabbagh, M., Divan, G., Koh, Y. J., Kim, Y. S., Kauchali, S., Marcín, C., Montiel-Nava, C., Patel, V., Paula, C. S., Wang, C., Taghi Yasamy, M., \& Fombonne, E. (2012). Global prevalence of autism and other pervasive developmental disorders. Autism Research, 5(3), 160-179. http://doi.org/10.1002/aur.239

Eveslage, M. (2012). School social workers' perspectives on working with children with autism spectrum disorders [Unpublished master's thesis]. St Catherine University, St. Paul, MN. https://sophia.stkate.edu/cgi/viewcontent. cgi?article $=1022 \&$ context=msw_papers

Foster, M. V. (2015). School social workers' role in supporting parents of a child with autism [Unpublished master's thesis]. St Catherine University, St. Paul, MN. https://sophia.stkate.edu/cgi/viewcontent. cgi?article $=1449 \&$ context=msw_papers

Gill, P., Stewart, K. Treasure, E., \& Chadwick, B. (2008). Methods of data collection in qualitative research: Interviews and focus groups. British Dental Journal, 204, 291-295. https://www.nature.com/articles/bdj.2008.192

Gilgun, J. F. (1994). A case for case studies in social work research. Social Work, 39(4), 371-380. https://doi. org/10.1093/sw/39.4.371

Grasu, M. (2015). Practical aspects of the intervention on children with autism spectrum disorder. Scientific Annals of the Alexandru loan Cuza University. New Series Sociology and Social Work section, 8(1). https://anale. fssp.uaic.ro/index.php/asas/article/view/389/328

Greenwood, D., \& Lowenthal, D. (2005). Case study as a means of research social work and improving practitioner education. Journal of Social Work Practice, 19(2), 181-193. doi:10.1080/02650530500144782 
Hens, K. (2019). The many meanings of autism: Conceptual and ethical reflections. Developmental Medicine \& Child Neurology. https://onlinelibrary.wiley.com/doi/ full/10.1111/phc3.12559

Higgins, N. (2005). Changing school culture through action research and leadership. Waikato Journal of Education, 11(2), 17-37.

Hwang, S., Kim, Y. S., Koh, Y. J., \& Leventhal, B. L. (2018). Autism spectrum disorder and school bullying: Who is the victim? Who is the perpetrator? Journal of Autism and Developmental Disorders, 48(1), 225-238. https:// doi.org/10.1007/s10803-017-3285-z

Iannuzzi, D., Connors, S. L., Broder-Fingert, S., \& Kopecky, K. (2015). Addressing the needs of individuals with autism: Role of hospital-based social workers in implementation of a patient-centered care plan. Health and Social Work, (3), 245-249. https://academic.oup. com/hsw

lachini, A., Berkowitz, R., Moore, H., Pitner, R., Astor, R., \& Benbenishty, R. (2017). School climate and school social work practice. Encyclopaedia of social work. https://oxfordre.com/socialwork/view/10.1093/ acrefore/9780199975839.001.0001/acrefore9780199975839-e-1195

Karal, M. A., \& Wolfe, P. S. (2018). Social story effectiveness on social interaction for students with autism: A review of the literature. Education and Training in Autism and Developmental Disabilities, 53(1), 44-58.

Kayama, M., \& Haight, W. (2014). Disability and stigma: How Japanese educators help parents accept their children's differences. Social Work, 59(1), 24-33. doi:10.1093/sw/ swt027

Kids Health. (n.d.). Autism spectrum disorder (ASD). https:// www.kidshealth.org.nz/autism-spectrum-disorder-asd

Klusek, J., Martin, G. E., \& Losh, M. (2014). A comparison of pragmatic language in boys with autism and fragile $X$ syndrome. Journal of Speech, Language, and Hearing Research, 57(5), 1692-1707. doi:10.1044/2014_ JSLHR-L-13-0064

Manukau Institute of Technology. (2017). Manukau Institute of Technology guidelines for ethical approval. https:// canvas.manukau.ac.nz/courses/34492/ files/2400753? module_item_id=573394

Masten, C. L., Colich, N. L., Rudie, J. D., Bookheimer, S. Y., Eisenberger, N. I., \& Dapretto, M. (2011). An $\mathrm{fMRl}$ investigation of responses to peer rejection in adolescents with autism spectrum disorders. Developmental Cognitive Neuroscience, 1(3), 260-270. doi:10.1016/j.den.2011.01.004

McLean, M. T. (2011, Summer). Marion's message: Working internationally: How to identify (and avoid) cultural imperialism. Midwifery Today, 8. https://ezproxy. manukau.ac.nz/login?url=https://search-proquest-com. ezproxy.manukau.ac.nz/docview/1417585594?account id $=43986$

Minhas, A., Vajaratkar, V., Divan, G., Hamdani, S. U., Leadbitter, K., Taylor, C., Aldred, C., Tariq, A., Tariq, M. Cardoza, P., Green, J., Patel, V., \& Rahman, A. (2015). Parents' perspectives on care of children with autistic spectrum disorder in South Asia: Views from Pakistan and India. International Review of Psychiatry, 27(3), 247-256. doi:10.3109/09540261.2015.1049128
Oberman, L. (2008). Neurodiversity: Does ASD need treatment or does society need to accept autism as an "alternative way of being?" https://www.psychologytoday. com/us/blog/the-autism-spectrum/200807/neurodiversitydoes-asd-need-treatment-or-does-society-need-accept

Openshaw, L. (2018). Social work in schools: Principles and practice. Guilford Press.

Parsons, L., Cordier, R., Munro, N., Joosten, A., Speyer, R. (2017). A systematic review of pragmatic language interventions for children with autism spectrum disorder PLOS ONE, 12(4). https://doi.org/10.1371/journal. pone.0172242

Payne, M. (2014). Modern social work (4th ed.). Palgrave Macmillan.

Plavnick, J., Kaid, T., \& MacFarland, M. (2015). Effects of a school-based social skills training program for adolescents with autism spectrum disorder and intellectual disability. Journal of Autism and Developmental Disorders, 45(9), 2674-2690. https://doi. org/10.1007/s10803-015-2434-5

Ponelis, S. R. (2015). Using interpretive qualitative case studies for exploratory research in doctoral studies: A case of information systems research in small and medium enterprises. International Journal of Doctoral Studies, 10, 535-550. http://ijds.org/Volume10/ IJDSv10p535-550Ponelis0624.pdf

Preble, B., \& Gordon, R. (2011). Transforming school climate and learning: Beyond bullying and compliance. Corwin.

Ripamonti, L. (2016). Disability, diversity, and autism: Philosophical perspectives on health. The New Bioethics, 22(1), 56-70. doi:10.1080/20502877.2016.1 151256

Robert-Domolaize. L. (2019, February 2). When your autistic child's biggest bullies are other parents. The Washington Post. https://www.washingtonpost.com/ lifestyle/2019/02/01/when-your-autistic-childs-biggestbullies-are-other-parents/

Robison, J.E. (2008). Look me in the eye. Bantam. Overdrive.com

Robison, J. E. (2013). What is neurodiversity? https://www. psychologytoday.com/nz/blog/my-life-aspergers/201310/ what-is-neurodiversity

Rotheram-Fuller, E., Kasari, C., Chamberlain, B., \& Locke J. (2010). Social involvement of children with autism spectrum disorders in elementary school classrooms. Journal of Child Psychology and Psychiatry, and Allied Disciplines, 51(11), 1227-1234. doi:10.1111/j.14697610.2010.02289.x

Scattone, D. (2007). Social skills interventions for children with autism. Psychology in the Schools, 44(7), 717-726. https://doi.org/10.1002/pits.20260

Shavrina, N. (2014). Beyond the others' world: An essay about the experience of social work with a diagnosis of Asperger syndrome. Journal of Comparative Social Work, 9(1). http://journal.uia.no/index.php/JCSW/article/ view/277/212

Shearer, J., Butcher, C., \& Pearce, A. (2006). Quality educational practice for students with Asperger's syndrome. https://www.education.sa.gov.au/sites/g/files/ net691/f/educational-practices-students-aspergers.pdf

Shepherd, D., Landon, J., \& Goedeke, S. (2017). Symptom severity, caregiver stress and intervention helpfulness 
assessed using ratings from parents caring for a child with autism. Autism, 22(5), 585-596. doi. org/10.1177/1362361316688869

Sheridan, M. C. (2012). A comparison of group verses individual therapy on the output of appropriate utterances in a six-year-old girl with autism: A case study. [Unpublished master's thesis]. University of Kentucky. https://uknowledge.uky.edu/rehabsci_etds/5

Suresh, P. (2018). Global prevalence of autism: A mini-review. SciFed Journal of Autism. 2(1). http:// scifedpublishers.com/fulltext/global-prevalence-ofautism-a-mini-review/22170

Sussman, J. L. (2008). What is autism? Total Health, 30 29-31. https://ezproxy.manukau.ac.nz/login?url=https:// search-proquest-com.ezproxy.manukau.ac.nz/docview/2 10169128 ? accountid $=43986$

Terry, K. (2015). A wrinkle in the fold: Inclusion of people with autism spectrum disorders in faith communities Social Work \& Christianity, 42(4), 449-469. https://www. nacsw.org/

Testa, D. (2011). School social work: A school-based field placement. Aotearoa New Zealand Social Work, 23(4), 14-23.

Thanh, N. C., \& Thanh, T. T. L. (2015). The interconnection between interpretivist paradigm and qualitative methods in education. American Journal of Educational Science, 1(2), 24-27. https://pdfs.semanticscholar.org/79e6/888e 672cf2acf8afe2ec21fd42a29b2cbd90.pdf

Thomas, C. (2012). Theorising disability and chronic illness: Where next for perspectives in medical sociology? Social Theory and Health, 10, 209-228. https://doi.org/10.1057/ sth.2012.7

Ungar, M. (2002). A deeper, more social ecological social work practice. Social Service Review, 76(3), 480-497. https://doi-org.ezproxy.manukau.ac.nz/10.1086/341185

Vaismoradi, M.,Turunen, H., \& Bondas, T. (2013). Content analysis and thematic analysis: Implications for conducting a qualitative descriptive study. Nursing \& Health Sciences, 15(3), 398-405. https://doi.org/10.1111/ nhs. 12048

Vanbergeijk, E. O., \& Shtayermman O. (2005). Asperger's syndrome, Journal of Human Behavior in the Social Environment, 12(1), 23-37. doi:10.1300/J137v12n01_02

Young, I. M. (2003). Five faces of oppression. In L. Heldke \& P. O'Connor (Eds.), Oppression, privilege, and resistance: Theoretical perspectives on racism, sexism, and heterosexism (pp. 37-64). https://www.sunypress. edu/pdf/62970.pdf 